\title{
An Anchored Open-Ended Survey Approach in Multiple Case Study Analy- sis
}

\section{Dr. Walter C. Lee, Virginia Tech}

Dr. Walter Lee is an Assistant Professor in the Department of Engineering Education and the Assistant Director for Research in the Center for the Enhancement of Engineering Diversity (CEED), both at Virginia Tech. Lee's research interests include co-curricular support, student success and retention, and diversity in STEM. He received his Ph.D in Engineering Education from Virginia Tech, M.S. in Industrial \& Systems Engineering from Virginia Tech, and B.S. in Industrial Engineering from Clemson University.

\section{Mr. Benjamin David Lutz, Virginia Tech}

Ben Lutz is a PhD student in the Department of Engineering Education at Virginia Tech. His research interests include design teaching and learning, mentoring in design and project work, student experiences in engineering design, the transition from engineering school into the workplace, and also efforts for inclusion and diversity within engineering. His current work is in related understanding how students describe their own learning in engineering, and how that learning supports transfer of learning from school into professional practice as well as exploring students' conceptions of diversity and its importance within engineering fields. 


\section{An Anchored Open-Ended Survey Approach in Multiple Case Study Analysis}

\section{Introduction}

Surveys are ubiquitous in educational research; this data collection method is used to examine a wide range of topics, including behaviors, attitudes ${ }^{1}$, perceptions ${ }^{2}$, and many other aspects of students and their experiences. Surveys are also used to make inferences and predictions about populations that would otherwise be too large to examine ${ }^{3}$. By asking questions to a representative sample of a population, statistical tools can help generalize results. Furthermore, question type can, and often does, vary within and across surveys, with typical formats being sliding scales (e.g., Likert scales) and categorical responses (e.g., structured or fixed response questions). In addition to these closed-ended formats, researchers also use open-ended questions. Open-ended questions can be added onto existing fixed-choice questions (e.g., including an "other" option that allows respondents to specify an answer excluded from the choices), or used as a standalone question (i.e., where respondents are not provided any answer options whatsoever and must write or type in their response). For example, a researcher could use a closed-ended question to ask for a respondent's level of education and offer choices ranging from "high school" to a "doctoral degree" while providing the "Other" option or simply ask, "What is your highest level of education?" without providing any answer choices. As is the case with research methods or designs broadly, the purpose of a particular study should guide choices regarding format of questions in a survey instrument ${ }^{4}$.

While both question formats (i.e., closed- and open-ended) are used in survey research, closedended questions tend to be more prevalent; open-ended questions, when present, tend to be used as "venting" or "catch-all" items. Nevertheless, it is important to note that both kinds of questions have advantages and drawbacks as it relates to survey design, question development, and analysis of responses. The purpose of this paper is to describe a pragmatic response to the methodological drawbacks of both approaches. Specifically, we will discuss the use of anchored open-ended ( $A O E$ ) questions - where the response to a closed-ended question serves as a foundation (or anchor) for an accompanying response to an open-ended question. To situate this contribution, we first discuss both closed- and open-ended question formats in survey research, justification for their use, and the relative affordances and challenges associated with both approaches. Second, we describe a multi-case study in which the AOE questions were developed and implemented. This will include a discussion of the data collection and analysis procedures that accompanied this novel approach to exploring student perceptions and a sample of the results. Lastly, we conclude with a summary of the AOE approach, discussion of its advantages and limitations, and synopsis of future directions and possible applications of AOE questions.

\section{Literature Review}

As noted above, survey questions come in various formats, most of which can be categorized as open- or closed-ended. While both approaches can provide useful data, it is important to consider the relative affordances and drawbacks of each because the question format will influence the nature of data that is collected, the analyses that can be implemented, and the conclusions that can be reasonably drawn. The following sections will discuss both closed- and open-ended questions, including examples of and recommendations for their use in survey research. 


\section{Closed-ended Questions}

Closed-ended questions, which force respondents to select from a predetermined set of choices when responding to a particular item ${ }^{5}$, are common in survey instruments and familiar among most educational researchers. Some well-known examples are Likert questions, in which respondents are asked to rate their "level of agreement" with various statements ${ }^{6}$, and fixedchoice questions, in which respondents can select an answer from a list of options (e.g., political party affiliation) ${ }^{5}$. Researchers often rely on these types of questions for both their simplicity and their suitability to well-accepted quantitative analysis techniques ${ }^{7}$.

There are many reasons for using closed-ended survey questions. One particular advantage is that they provide a common baseline on which to analyze responses. That is, when respondents can only choose from a predetermined set of choices, more precise comparisons can be drawn across samples or time periods ${ }^{3}$. There are also instances when closed-ended questions provide the most useful data. For example, when measuring well-understood constructs like self-efficacy ${ }^{8}$, the most direct strategy is to ask respondents to rank their level of confidence numerically or categorically - as opposed to asking them to describe, in their own words, how confident they feel. When scores can be recorded and tabulated numerically, the results can be analyzed using a wide range of scientifically accepted statistical techniques (e.g., T-tests, ANOVA). Closed-ended questions are especially useful when sampling large numbers of respondents because quantitative approaches to data collection and analysis are typically less resource-intensive than their qualitative counterparts.

Nonetheless, closed-ended questions are susceptible to methodological issues. Forcing respondents to choose from a fixed list of options may result in researchers overlooking salient themes or issues. For example, in a study exploring the differences of open- and closed-ended questions, Reja and colleagues ${ }^{9}$ asked Internet users "What is the most important, critical problem the Internet is facing today?" Respondents were either given (1) a closed-ended question that prompted them to select from 11 different choices (including an "other... write in") or they were given (2) an open-ended question that prompted them to type their answer in a text box. While the responses to the open-ended question format did mention all but one of the choices available to those responding to the equivalent closed-ended question, they also added a significant amount of new categories that the researchers had not anticipated. Thus, while closedended questions may be more economically collected and analyzed than the same question asked in an open-ended format, they remain subject to biases in question development, especially as it pertains to available answer choices.

In summary, when constructs or phenomena of interest are well understood, closed-ended questions can offer high levels of reliability and consistency in data analysis and give researchers a high degree of control in terms of responses that can be expected. However, closed-ended questions potentially overlook salient themes in participant responses (i.e., data) when constructs or phenomena are less understood or more variable. 


\section{Open-ended Questions}

Open-ended questions, which allow respondents to construct their own answers when responding to a particular question or prompt ${ }^{5}$, are frequently used in survey research also. A well-known example is venting questions ${ }^{10}$, which are placed at the end of survey instruments and are designed to allow participants to contribute additional information that they might deem noteworthy or relevant that the survey itself did not cover. Researchers also ask open-ended questions when the range of possible responses is not well understood (as may be the case in exploratory studies such as the one presented here) ${ }^{5}$. Researchers often rely on these types of questions when the goal is to explore new spaces or contexts in which salient concepts are not well defined.

While the responses to open-ended questions provide respondents with additional freedom in answering a question, it is often unclear if or how the responses themselves should be used during analysis. Researchers have attempted to systematize the analysis of open-ended questions. For example, Mossholder and colleagues ${ }^{11}$ used textual data analysis (TDA), which includes frequency counting techniques, to explore relationships between responses to open- and closedended survey questions measuring workplace affect measures. Their approach uncovered correlations between quantitative responses and the textual data provided by the open-ended questions, demonstrating the efficacy of both the analytical approach (i.e., TDA) and open-ended questions. Jackson and Trochim ${ }^{12}$ also developed a novel approach to analyzing the content of open-ended responses. Using text-sorting algorithms, the authors developed conceptually distinct clusters of responses and sorted them to create concept maps, demonstrating links and relationships between perceptions of workplace team norms and respondent profile. In general, TDA and other quantitizing approaches can provide correlations or describe conceptual relationships, but the assumptions associated with frequency counts comes with its own methodological issues. Just because a word or phrase is uttered more than another does not necessarily imply that it is more salient or important to a participant's response. Thus, while efforts have been made to collect and analyze responses to open-ended survey questions, the lack of agreement regarding appropriate (or even perhaps useful) techniques remains a challenge for researchers.

Open-ended questions allow researchers to uncover concepts that a closed-ended question might overlook. When concepts are not well-understood, open-ended questions "open the floor" to participants, providing critical insight into emerging research areas. Still, development of a systematic, agreed-upon analysis technique for these responses remains a challenge of the broader research community: current strategies often entail turning qualitative data into quantitative data, which is accompanied by myriad assumptions and biases. Given this fact, the aim of this paper is to introduce an innovative, pragmatic analysis technique that preserves the meaning of open-ended responses while remaining "anchored" to a quantitative measure.

\section{Data Collection Process}

The analytical approach described here is part of a larger study ${ }^{13}$ that used Tinto's Model of Institutional Departure ${ }^{14}$ as a theoretical lens to explore how student interventions offered alongside engineering curricular influence the undergraduate experience. To address this purpose, the study involved anchored open-ended questions, document artifacts, individual 
interviews, and focus groups to examine six Engineering Student Support Centers (ESSCs) from three different ESSC classifications: Multicultural or Minority Engineering Programs (MEP), Women in Engineering Programs (WEP), and Diversity in Engineering Programs (DEP). This manuscript focuses on the data collected from each of the six cases using AOE questions.

It should be noted that the lead author on this paper distributed the AOE survey instrument to students to primarily recruit potential focus group participants; collecting information about their individual (or isolated) experiences with their respective ESSC was not the driving force. The AOE questions analyzed in this manuscript were added to the recruitment instrument based on the belief that if students were willing to visit the link, they would also be willing to complete a few short questions. Thus, in addition to being asked if they would like to be contacted about the possibility of participating in a focus-group interview, students were asked to indicate whether the ESSC at their institutions had positively, negatively, or not influenced them with regard to five Output areas ${ }^{13}$ in Table 1 below. Importantly, for each question, students were also provided an opportunity (via an open-ended question) to explain their answer to the close-ended question, requesting specific examples if possible. The combination of a question prompt, corresponding answer choices, and subsequent open-ended question represent an AOE question.

Table 1: Survey Sample

\begin{tabular}{|c|c|c|}
\hline Output Areas & Question Prompt & Answer Choices \\
\hline $\begin{array}{c}\text { Faculty/staff } \\
\text { Interaction }\end{array}$ & $\begin{array}{l}\text { With regards to the } \\
\text { interactions you have with } \\
\text { engineering faculty and } \\
\text { staff, which of the } \\
\text { following statements do } \\
\text { you agree with: }\end{array}$ & $\begin{array}{l}\text { a. [ESSC] has positively influenced my interactions } \\
\text { with engineering faculty/staff } \\
\text { b. [ESSC] has not influenced my interactions with } \\
\text { engineering faculty/staff } \\
\text { c. [ESSC] has negatively influenced my interactions } \\
\text { with engineering faculty/staff }\end{array}$ \\
\hline $\begin{array}{l}\text { Peer-group } \\
\text { Interaction }\end{array}$ & $\begin{array}{l}\text { With regards to the } \\
\text { interactions you have with } \\
\text { other students, which of } \\
\text { the following statements } \\
\text { do you agree with: }\end{array}$ & $\begin{array}{l}\text { a. [ESSC] has positively influenced my interactions } \\
\text { with other students } \\
\text { b. [ESSC] has not influenced my interactions with other } \\
\text { students } \\
\text { c. [ESSC] has negatively influenced my interactions } \\
\text { with other students }\end{array}$ \\
\hline $\begin{array}{c}\text { Academic } \\
\text { Performance }\end{array}$ & $\begin{array}{l}\text { With regards to your } \\
\text { academic performance, } \\
\text { which of the following } \\
\text { statements do you agree } \\
\text { with: }\end{array}$ & $\begin{array}{l}\text { a. [ESSC] has positively influenced my academic } \\
\text { performance } \\
\text { b. [ESSC] has not influenced my academic performance } \\
\text { c. [ESSC] has negatively influenced my academic } \\
\text { performance }\end{array}$ \\
\hline $\begin{array}{l}\text { Extracurricular } \\
\text { Involvement }\end{array}$ & $\begin{array}{l}\text { With regards to your } \\
\text { participation in } \\
\text { extracurricular activities, } \\
\text { which of the following } \\
\text { statements do you agree } \\
\text { with: }\end{array}$ & $\begin{array}{l}\text { a. [ESSC] has positively influenced my participation in } \\
\text { extracurricular activities } \\
\text { b. [ESSC] has not influenced my participation in } \\
\text { extracurricular activities } \\
\text { c. [ESSC] has negatively influenced my participation in } \\
\text { extracurricular activities }\end{array}$ \\
\hline $\begin{array}{c}\text { Professional } \\
\text { Development }\end{array}$ & $\begin{array}{l}\text { With regards to your } \\
\text { professional development, } \\
\text { which of the following } \\
\text { statements do you agree } \\
\text { with: }\end{array}$ & $\begin{array}{l}\text { a. [ESSC] has positively influenced my professional } \\
\text { development } \\
\text { b. [ESSC] has not influenced my professional } \\
\text { development } \\
\text { c. [ESSC] has negatively influenced my professional } \\
\text { development }\end{array}$ \\
\hline
\end{tabular}




\section{Analysis Process}

Before beginning analysis, we downloaded the survey responses and created an individual excel spreadsheet for each case. This was done to isolate the responses based on which ESSC students were referring to and resulted in a total of six spreadsheets that contained the responses to both the open-ended and closed-ended questions included in the instrument. Once the data was collected, the following steps were completed. (It is important to note that while we present each step in a linear and succinct fashion, the progression of the data analysis in the larger study was much more iterative.)

\section{Step 1. Data Isolation}

The purpose of Step 1 was to remove the need to interpret whether a student perceived an experience as positive, negative, or neutral. Close-ended responses (or the anchor) were used to sort participant responses to open-ended questions in the Excel spreadsheets. Once sorted, we imported the responses to the open-ended survey into a word document for each Output area. In each document, responses were clustered into individual tables that represented positive, neutral, or negative perceptions (see Tables 2-4). Step 1 resulted in a total of 30 documents, representing 5 Output areas across each of the six cases.

Table 2: Academic Explanations - Positive Examples

\begin{tabular}{|c|l|}
\hline \multicolumn{1}{|c|}{ Student ID } & \multicolumn{1}{c|}{ Explanation } \\
\hline 20 & $\begin{array}{l}\text { The mentorship program helped me prepare for my classes. I was able to meet with an } \\
\text { older engineering student who had taken many of the classes I needed and I learned from } \\
\text { her experiences. }\end{array}$ \\
\hline 154 & $\begin{array}{l}\text { Being able to walk out into the hallway to ask for homework questions or find study } \\
\text { buddies made a world of difference in my studies. Engineering is a very difficult } \\
\text { discipline, and by living surrounded by others going through the same things we were all } \\
\text { able to get through it together by helping one another. }\end{array}$ \\
\hline 159 & Helped me when I was a freshman to develop good study habits \\
\hline
\end{tabular}

Table 3: Academic Explanations - Negative Examples

\begin{tabular}{|c|l|}
\hline Student ID & \multicolumn{1}{c|}{ Explanation } \\
\hline 17 & $\begin{array}{l}\text { Not being in a [ESSC] program has separated me from all of the other engineers. I chose } \\
\text { not to participate in one due to wanting to meet other people from other majors and not } \\
\text { have competition within the dorm, and it has really left me at a disconnect to other female } \\
\text { engineers. It's like they disapprove of my decision. }\end{array}$ \\
\hline 49 & $\begin{array}{l}\text { From what I've heard, the mandatory classes/events/mentoring sessions are more of a } \\
\text { waste of time than help. The mentors are often sophomores that are taking the same } \\
\text { courses as the advanced students in the communities (meaning they can't help). And the } \\
\text { fact that they are required for everyone wastes some of the students' time. }\end{array}$ \\
\hline 212 & $\begin{array}{l}\text { I have always been a good student; however, the design of the [ESSC] classes is so } \\
\text { convoluted and flipped that it is almost impossible to do well based on intelligence, to } \\
\text { succeed you simply need to jump through a series of time consuming hoops. }\end{array}$ \\
\hline
\end{tabular}


Table 4: Academic Explanations - Neutral Examples

\begin{tabular}{|c|l|}
\hline Student ID & \multicolumn{1}{c|}{ Explanation } \\
\hline 1 & I am unsure if it's impacted me. \\
\hline 112 & My academic performance was my own fault. \\
\hline 179 & I have not taken part in a [ESSC] program \\
\hline
\end{tabular}

\section{Step 2. Unitizing}

The purpose of Step 2 was to develop discrete statements that represented the range of responses that students provided to the survey questions. To remove redundancy, we completed the process of unitizing ${ }^{15}$ by generating single-concept statements to represent the student responses. Examples of this process are illustrated in Table 5 below. We completed this process until a single-concept statement could represent every student response across all 30 documents. This resulted in a list of positive, negative, and neutral statements for each of the five Output areas.

Table 5 - Unitizing Examples

\begin{tabular}{|c|c|}
\hline Student Explanation & Single-concept Student Statement \\
\hline \multirow{2}{*}{$\begin{array}{l}\text { Being able to walk out into the hallway to ask for } \\
\text { homework questions or find study buddies made a } \\
\text { world of difference in my studies. Engineering is a } \\
\text { very difficult discipline, and by living surrounded by } \\
\text { others going through the same things we were all able } \\
\text { to get through it together by helping one another. }\end{array}$} & $\begin{array}{l}\text { I had access to students whom I could ask for academic } \\
\qquad \text { assistance (+) }\end{array}$ \\
\hline & $\begin{array}{l}\text { I have an easier time forming study groups and finding } \\
\text { people to work with academically }(+)\end{array}$ \\
\hline $\begin{array}{l}\text { Helped me when I was a freshman to develop good } \\
\text { study habits }\end{array}$ & $\begin{array}{l}\text { I learned how to study and prepare for exams more } \\
\text { effectively }(+)\end{array}$ \\
\hline $\begin{array}{l}\text { From what I've heard, the mandatory } \\
\text { classes/events/mentoring sessions are more of a waste } \\
\text { of time than help. The mentors are often sophomores } \\
\text { that are taking the same courses as the advanced } \\
\text { students in the communities (meaning they can't help). } \\
\text { And the fact that they are required for everyone wastes } \\
\text { some of the students' time. }\end{array}$ & $\begin{array}{l}\text { I spent less time studying than I should have due to the } \\
\text { additional time-commitments (-) }\end{array}$ \\
\hline I am unsure if it's impacted me. & $\begin{array}{l}\text { I am unsure how or if I was influenced though I was } \\
\text { involved }(+/-)\end{array}$ \\
\hline
\end{tabular}

\section{Step 3 - Theme Verification and Triangulation}

The purpose of Step 3 was twofold: (1) to identify themes within each Output area based on the single-concept statements from Step 2 and (2) to triangulate findings from another part of the larger study (not presented here). In the larger study, we collected data from ESSC administrators through individual interviews. Through coding these interviews, we identified themes that described the methods used to support students. To triangulate these findings, we compared the single-concept statements from Step 2 to these themes under the assumption that the responses students provide should closely align with those provided by educators, modifying 
these themes where necessary. An example of single-concept statements mapping to a theme is illustrated below in Table 6 .

Table 6 - Theme Examples

\begin{tabular}{|c|c|}
\hline Single-concept Student Statement & Administrator Interview Theme \\
\hline $\begin{array}{l}\text { I had access to students whom I could ask for } \\
\text { academic assistance (+) }\end{array}$ & \multirow{3}{*}{ Academic Resources } \\
\hline $\begin{array}{l}\text { I have an easier time forming study groups and } \\
\text { finding people to work with academically }(+)\end{array}$ & \\
\hline $\begin{array}{l}\text { I received academic assistance from tutors/mentors } \\
(+)\end{array}$ & \\
\hline $\begin{array}{l}\text { I was encouraged to ask for academic help when } \\
\text { necessary }(+)\end{array}$ & \multirow{3}{*}{ Academic Information } \\
\hline $\begin{array}{l}\text { I received guidance on scheduling courses and } \\
\text { selecting instructors }(+)\end{array}$ & \\
\hline $\begin{array}{l}\text { I received information about the academic resources } \\
\text { available to me on campus }(+)\end{array}$ & \\
\hline
\end{tabular}

\section{Implications for Practice}

There were several advantages to using AOE questions in the survey instrument as a part of the multi-case study. First, AOE questions provided a quick and efficient way to get information. This was particularly advantageous since the experiences of individual students were of secondary concern in the larger study. By adding $5 \mathrm{AOE}$ questions to a recruitment instrument, the lead author was able to collect a substantial amount of extra data that provided valuable insight into student perceptions and experiences (see Table 7).

Table 7 - Surveys Completed

\begin{tabular}{|c|c|}
\hline Case & $\begin{array}{c}\text { Surveys } \\
\text { Completed }\end{array}$ \\
\hline 1 & 245 \\
\hline 2 & 57 \\
\hline 3 & 20 \\
\hline 4 & 111 \\
\hline 5 & 46 \\
\hline 6 & 59 \\
\hline Total & 538 \\
\hline \multicolumn{2}{|c|}{$\begin{array}{c}\text { Note: A survey was considered } \\
\text { complete as long as the close-ended } \\
\text { questions were answered. }\end{array}$} \\
\hline
\end{tabular}


Second, AOE questions provided students with specific answer choices while allowing them to provide qualitative feedback. This was beneficial given the exploratory nature of the study and the likelihood of students providing short answers to open-ended survey questions. Since an anchor accompanied each open-ended response, it was easier to interpret short responses. This also allowed students, who may have otherwise not completed an open-ended survey, to provide feedback by answering the close-ended questions even if they did not want to provide an explanation. While this did not result in data that could be analyzed using the process described above, it allowed the researcher to get a better understanding of the general perspectives with regard to impact being positive, negative, or neutral by coding responses as either $1,-1$, or 0 (respectively) and then calculating descriptive statistics. For example, based on Table 8, we can conclude that Case 1 had a more positive impact on peer-group interactions than faculty-staff interactions. This conclusion could not have been reached with open-ended responses only.

Table 8 - Descriptive Statistics

\begin{tabular}{|c|c|c|c|c|c|c|}
\hline Case & & $\begin{array}{l}\text { Faculty-staff } \\
\text { Interactions }\end{array}$ & $\begin{array}{l}\text { Peer-group } \\
\text { Interactions }\end{array}$ & $\begin{array}{c}\text { Academic } \\
\text { Performance }\end{array}$ & $\begin{array}{l}\text { Extracurricular } \\
\text { Involvement }\end{array}$ & $\begin{array}{l}\text { Professional } \\
\text { Development }\end{array}$ \\
\hline \multirow[t]{3}{*}{1} & Mean & .58 & .86 & .67 & .44 & .78 \\
\hline & $\mathrm{N}$ & 156 & 156 & 156 & 156 & 156 \\
\hline & Std. Deviation & .507 & .367 & .486 & .559 & .419 \\
\hline \multirow[t]{3}{*}{2} & Mean & .39 & .68 & .65 & .49 & .49 \\
\hline & $\mathrm{N}$ & 57 & 57 & 57 & 57 & 57 \\
\hline & Std. Deviation & .526 & .469 & .481 & .539 & .539 \\
\hline \multirow[t]{3}{*}{3} & Mean & .75 & .80 & .80 & .55 & .80 \\
\hline & $N$ & 20 & 20 & 20 & 20 & 20 \\
\hline & Std. Deviation & .444 & .410 & .410 & .510 & .410 \\
\hline \multirow[t]{3}{*}{4} & Mean & .50 & .71 & .37 & .55 & .72 \\
\hline & $\mathrm{N}$ & 111 & 111 & 111 & 111 & 111 \\
\hline & Std. Deviation & .502 & .529 & .485 & .500 & .451 \\
\hline \multirow[t]{3}{*}{5} & Mean & .65 & .80 & .59 & .52 & .67 \\
\hline & $\mathrm{N}$ & 46 & 46 & 46 & 46 & 46 \\
\hline & Std. Deviation & .482 & .401 & .498 & .547 & .474 \\
\hline \multirow[t]{3}{*}{6} & Mean & .64 & .69 & .67 & .28 & .64 \\
\hline & $\mathrm{N}$ & 39 & 39 & 39 & 39 & 39 \\
\hline & Std. Deviation & .486 & .569 & .478 & .560 & .486 \\
\hline \multirow[t]{3}{*}{ Total } & Mean & .56 & .77 & .59 & .47 & .70 \\
\hline & $\mathrm{N}$ & 429 & 429 & 429 & 429 & 429 \\
\hline & Std. Deviation & .507 & .456 & .498 & .540 & .463 \\
\hline
\end{tabular}


Third, using AOE questions removed some of the barriers of getting quantitative and qualitative data in a case study. As previously mentioned, the primary purpose of the survey instrument was to recruit participants for focus groups. By including AOE questions, we were able to collect data from a larger sample of students, including data from both students who did not want to participate in the focus groups and those who did not want to complete the open-ended questions, while giving each student the option to do both.

Lastly, AOE questions facilitated the process described above and allowed us to generate singleconcept statements that potentially represent future closed-ended questions. This was particularly useful in a multi-case study because it provided a foundation for developing survey instruments that could be used to evaluate the ESSCs included in the study in the future.

\section{Discussion}

As with any analytical approach, AOE questions are accompanied by their own advantages and drawbacks. By blending open- and closed-ended approaches, we alleviate some methodological issues, while also introducing challenges that warrant further consideration. Still, as noted above, it is the purpose of the research that should guide the approaches to data collection and analysis, and the authors have developed a novel tool for educational research.

\section{Advantage 1 - Response interpretation is facilitated}

AOE questions appear to mitigate the uncertainty and ambiguity involved in interpreting answers to questions that are either only open- or closed- ended. Analyzing closed-ended questions relies on the assumption that the respondent correctly interpreted both the question and the available answer choices. On the other hand, a response to a purely open-ended question is subject to misinterpretations by researchers and analysis heavily relies on the researcher identifying connections between responses. When exploring student perceptions, AOE questions can provide insight into dimensions of a system and explain not only how different aspects are perceived (the anchor), but also why they are perceived that way (the open-ended response). Take, for example, the data presented here. If questions simply asked respondents to describe their interactions regarding different Output Areas, researchers would have to make a decision as to whether that experience was perceived as helpful or detrimental. Because each open-ended response is anchored to a quantitative response, researchers can more quickly and accurately sort responses for quicker and deeper analysis. Further, the presence of open-ended responses make it easier to determine the intent behind a close-ended response. Here, AOE questions leverage the openended response to provide clarification regarding why the respondent selected the anchor. For example, "neutral" impact was often reported as the result of students seeking support elsewhere (i.e., not within the ESSC being discussed in the survey) as opposed to having both positive and negative experiences in an area that canceled each other out. If students had only been asked to provide a numerical response with no open-ended support, results could be misinterpreted. This is particularly useful for survey development, as AOE responses can help researchers understand the different interpretations respondents can have to the same questions, reducing response ambiguity and potentially enhancing question clarity in subsequent iterations. 


\section{Advantage 2 - Future work is accelerated}

The single-concept statements that emerge from the AOE analysis can provide a starting point for closed-ended question development. As in the exploratory study presented here, AOE questions can help researchers acquire the preliminary data needed to construct more focused survey questions on particular aspects of an experience. As demonstrated, the unitizing process can create a list of items that can be fairly easily converted to closed-ended questions, thus making subsequent data collection more efficient. For example, one can imagine converting the single-concept statements in Tables 5 and 6 into Likert-type questions and creating a survey that is easier to distribute to larger populations.

\section{Disadvantage - Survey fatigue is possible}

This approach asks respondents to answer, in series, a closed-ended question immediately followed by an open-ended question. From a participant point-of-view, a longer version of a survey instrument similar to that presented here seems draining, with lots of switching between clicking and typing. This issue raises important questions about instrument length, concept coverage, completion rate, and respondent exhaustion. As a result, the authors of the paper (1) recommend limiting $\mathrm{AOE}$ questions to topics for which the range of answers cannot reasonably be anticipated and (2) discourage researchers from including more than 6-7 questions.

\section{Conclusion}

The authors have presented a novel approach to exploring student perceptions across multiple settings. This approach asked participants to talk about whether the co-curricular support provided by an ESSC at their institution impacted their institutional experience in a positive, negative, or neutral manner. Future studies could use a similar question format to explore various perceptions along other binary or trinary scales (e.g., supportive/unsupportive, helpful/indifferent/unhelpful, pleased/neutral/displeased). While the authors demonstrated the use of $\mathrm{AOE}$ questions in multicase studies specifically, we believe that this approach to data collection and analysis has broader utility in exploratory education research.

\section{Acknowledge}

The authors thank Dr. Holly Matusovich for contributing to this study. Also, this material is based upon work supported by the National Science Foundation (NSF) as a Graduate Research Fellowship. Any opinions, findings, and conclusions in this material are those of the authors and do not necessarily reflect the views of the National Science Foundation

\section{References:}

1. M. Gläser-Zikuda and S. Järvelä, Application of qualitative and quantitative methods to enrich understanding of emotional and motivational aspects of learning, International journal of educational research, 47(2), 2008, pp. 79-83. 
2. K. E. Winters, H. M. Matusovich, M. S. Brunhaver, H. L. Chen, K. Yasuhara and S. Sheppard, From Freshman Engineering Students to Practicing Professionals: Changes in Beliefs about Important Skills over Time, Proceedings of the 2013 American Society for Engineering Education Annual Conference \& Exposition, Atlanta, GA, June, 2013, pp. 23-26.

3. E. J. Pedhazur and L. P. Schmelkin, Measurement, design, and analysis: An integrated approach, Series Psychology Press, 2013.

4. T. Teo, Handbook of quantitative methods for educational research, Series, 1, Sense Publishers, Rotterdam, The Netherlands, 2013.

5. L. M. Rea and R. A. Parker, Designing and conducting survey research: A comprehensive guide, Series John Wiley \& Sons, 2014.

6. J. T. Croasmun and L. Ostrom, Using Likert-Type Scales in the Social Sciences, Journal of Adult Education, 40(1), 2011, pp. 19.

7. D. Muijs, Doing quantitative research in education with SPSS, Series Sage, 2010.

8. J. S. Eccles and A. Wigfield, Motivational beliefs, values, and goals, Annual review of psychology, 53(1), 2002, pp. 109-132.

9. U. Reja, K. L. Manfreda, V. Hlebec and V. Vehovar, Open-ended vs. close-ended questions in web questionnaires, Developments in applied statistics, 19, 2003, pp. 159-177.

10. L. M. Rea and R. A. Parker, Designing \& conducting survey research: A comprehensive guide, 3, Series Jossey-Bass, San Francisco, CA, 2005.

11. K. W. Mossholder, R. P. Settoon, S. G. Harris and A. A. Armenakis, Measuring emotion in openended survey responses: An application of textual data analysis, Journal of management, 21(2), 1995, pp. 335-355.

12. K. M. Jackson and W. M. Trochim, Concept mapping as an alternative approach for the analysis of open-ended survey responses, Organizational Research Methods, 5(4), 2002, pp. 307-336.

13. W. C. Lee, Providing Co-Curricular Support: A Multi-Case Study of Engineering Student Support Centers, in Department of Engineering Education2015, Virginia Polytechnic Institute and State University.

14. V. Tinto, Leaving college: Rethinking the causes and cures of student attrition, 2nd, Series University of Chicago, Chicago, IL, 1994.

15. K. J. Srnka and S. T. Koeszegi, From words to numbers: How to transform qualitative data into meaningful quantitative results, Schmalenbach Business Review, 59(1), 2007, pp. 29-57. 